Pre-print version of the article: Bova, A. (2020). Dialogical construction of parental feeding strategies during family mealtimes. Journal of Health Psychology. doi: 10.1177/1359105319884600

\title{
Dialogical construction of parental feeding strategies during family mealtimes.
}

\begin{abstract}
This study focuses on social interactions during family mealtimes to examine the types of arguments used by parents to convince their children to eat. The results of this study show that feeding practices during mealtimes are dialogically constructed by parents and children together. Parents mostly used arguments based on the quality and quantity of food, adapting their language to the child's level of understanding. Future research might consider the observations and the subtle qualitative analyses of social interactions among family members as examples of possible ways to recognize the dialogical construction of feeding practices during mealtimes.
\end{abstract}

Keywords: argumentation, feeding practices, food-negotiation, parent-child interaction, qualitative research, social interactions 
Pre-print version of the article: Bova, A. (2020). Dialogical construction of parental feeding strategies during family mealtimes. Journal of Health Psychology. doi: 10.1177/1359105319884600

\section{Introduction}

Parental feeding practices during mealtimes and the way children respond to these practices have a crucial educational function within the family context (Black and Hurley, 2017; Blum-Kulka, 1997; Bova, 2019; Fulkerson et al., 2006). In particular, the activity of family mealtime is recognized as being an essential component of health promotion for children (Birch and Davison, 2001; Birch and Fisher, 2000; Draxten et al., 2014; Fiese et al., 2006; Fulkerson et al., 2008; Patton et al., 2006). There is a strong link between verbal communication and the feeding practices, since the action of evaluating the appropriate (or not appropriate) behavior concerning the food is often assumed as a topic of discourse (Alm et al., 2015; Laurier and Wiggins, 2011; Pan et al., 2000; Roach et al., 2017). For example, during family mealtimes, it is common to observe discussions in which the parents face their children's opposition to eat a particular food or more than a certain amount of a particular food, and other discussions in which the children ask their parents the permission to eat different food (Arcidiacono and Bova, 2015; Bova and Arcidiacono, 2014; Mondada, 2009; Wiggins, 2004a). The common aspect of these discussions is that in each of them parents and children engage in discussions around the topic of food in which they put forward arguments to convince the other party that their point of view is more valid and therefore deserves to be accepted.

Research on parental feeding practices during mealtimes highlight that parents adopt different strategies to convince their children to eat. The parenting feeding practices are correlated to the provision of a greater number of prompts or cues from the parent for their child to eat. The pressure to eat can vary from a strong verbal control, such as providing direct commands or corrections to a child, to a gentle verbal control such as suggestions or prompts to eat (Bova and Arcidiacono, 2013a; Brumark, 2008; Hubbs-Tait et al., 2008). Authoritarian patterns are considered as attempts to control children's eating with little regard for the children's individual preferences and choices (Drucker et al., 1999; Goodell et al., 2017; Loth et al., 2018). The authoritarian pattern is characterized by the frequent use of directives by parents, pressuring the child to eat healthy foods and restricting the intake of unhealthy foods (Patrick et al., 2005). On the contrary, a permissive feeding pattern can refer to allowing a child to make his or her own decisions regarding what, where, and how much to eat (Burnier et al., 2011; Scaglioni et al., 2008). However, some of the strategies that parents adopt to influence food preference and consumption in their children may have the opposite effect. In this regard, Hughes and colleagues (2011) suggest that parents' feeding practices may be a proxy for the emotional climate at mealtime, which may, in turn, influence the children's eating behaviors. In this regard, in a series of studies adopting various methodological approaches the pressure to eat was found to be ineffective at promoting food intake, while responsive feeding practices are associated with less food fussiness and more food enjoyment in children (Boutelle et al., 2001; Finnane et al., 2017; Morton et al., 1999; Pesch et al., 2018; Russell et al., 2015). 
Pre-print version of the article: Bova, A. (2020). Dialogical construction of parental feeding strategies during family mealtimes. Journal of Health Psychology. doi: 10.1177/1359105319884600

Despite some recent qualitative studies based on discourse, conversation, and argumentative analysis (e.g. Arcidiacono and Bova, 2015; Bova, 2015a, 2019; Bova and Arcidiacono, 2013b, 2015; Egbert, 1997; Foster et al., 2017; Foster et al., 2019; Goodwin, 1997; Lerner, 2002; Wiggins, 2004a, 2004b, 2013, 2014a), there is limited research in the domain that analyses family feeding practices during mealtimes in situ, since the majority of research on how parents and children negotiate about food during family mealtimes relies on interviews and selfreporting questionnaires. In research focused on family feeding practices during mealtimes, interviews and self-reporting questionnaires can provide much information on what family members think of specific topics. However, in this study, we are not interested in analyzing what family members think of particular issues but, instead, how food is negotiated by parents and children during mealtimes. By adopting a qualitative methodology including video-recordings and transcriptions of family mealtime conversations and inductive analysis of argumentative discursive sequences between parents and children, this study intends to show one of the possible paths to go toward this research direction. In line with other scholars (Kuhn, 1991; Voss and Van Dyke, 2001; Weigand, 2006), we refer to a single argument as a product and the dialogic argumentation as a process, the latter being implicit in the former. An argument, therefore, is always included within a "dialogic structure of negotiation which results on the basis of diverging views" (Weigand, 2006, p. 71), and it can be understood fully only if the entire argumentative dialogue is considered.

In all argumentative dialogues, including the ones between parents and children during mealtimes, the interlocutors choose the types of arguments that are useful either to support their standpoint or to weaken the interlocutor's standpoint. In this study, by "arguments" we refer to the arguments that are advanced by parents with the scope to support, explain, justify, and defend their directives. Most studies have considered the number of arguments advanced by participants as the sole indicator to examine their argumentative interactions. Hitherto, less attention has been paid to investigate the types of arguments used by parents to convince their children to eat. To start filling this gap in the literature on family feeding practices during mealtimes, in this study my focus is on the parents' generation of arguments during spontaneous argumentative dialogues with their children during mealtimes with the aim to answer the following research question: "What are the types of arguments most used by parents to convince their children to eat during mealtime?"

In this endeavor, we opted for a methodology based on the contemporary argumentation theory. The analytical approach for the analysis of the argumentative discussions between parents and children is, in fact, the pragma-dialectical ideal model of a critical discussion (van Eemeren and Grootendorst, 2004). According to this model, an argumentative discussion starts when the speaker advances his or her standpoint, and the listener casts doubts upon it or directly attacks the standpoint. Consequently, confrontation, in which disagreement regarding a certain standpoint is externalized in a discursive exchange or anticipated by the speaker, is a necessary condition for an argumentative discussion to occur. We believe that this model particularly fits 
Pre-print version of the article: Bova, A. (2020). Dialogical construction of parental feeding strategies during family mealtimes. Journal of Health Psychology. doi: 10.1177/1359105319884600

this study, and more generally, the study of argumentative interactions within the family context because it provides specific criteria for the selection of the argumentative discussions and the identification of the arguments put forth by family members. Although the differences in roles, age, and competences between parents and children certainly play an important role and must be carefully considered (see, for example, Tannen, 1990; Heller, 2014), the pragma-dialectical ideal model of a critical discussion has been already applied in previous studies regardless of the age differences between the interlocutors (e.g. Bova, 2015a, 2015b; Greco et al., 2018). The reason for this choice lies in the fact that using this model as a guide for the reconstruction produces an analytic overview of all components of an argumentative interaction, which points are at issue, and which arguments are advanced. The pragma-dialectical ideal model of a critical discussion is not used, instead, to evaluate children's argumentative capacity.

Moreover, in this study, we do not intend to highlight the characteristics of an argumentative parenting style compared to other parenting styles, or to determine which argument used by parents is more effective in convincing their children to eat (or not to eat). By taking a social constructionism stance on language (Billig, 1987; Edwards and Potter, 1992; Grace, 1987; Potter and Wetherell, 1987), we believe that the use of the pragma-dialectical ideal model of a critical discussion allows us to analyze how all the participants contribute to the construction of the argumentative discussion and the resolution of the difference of opinion. Accordingly, the focus is on the interaction between parents and children and on the dialogical process of food negotiation, rather than looking for a correlation between a particular argument and certain behavioral outcomes.

To present this study, the article is organized as follows: in its first part, the methodology on which our study is based is described. Afterward, the results of the analysis are presented. In the last part of the article, the conclusions drawn from this study and implication for research and practice are discussed.

\section{Methods}

\section{Data Corpus}

The data corpus is constituted by 30 video-recorded separate family meals (constituting about 20 hours of video data), constructed from two different sets of data, named sub-corpus 1 and subcorpus 2 .

Sub-corpus 1 consists of 15 video-recorded meals in five Italian families living in Rome. The creation of sub-corpus 1 (Italian families) took place from January to June 2004. The criteria adopted in the selection of the Italian families were the following: the presence of both parents and at least two children, of whom the younger is of preschool age (3- to 6-year old). All 
Pre-print version of the article: Bova, A. (2020). Dialogical construction of parental feeding strategies during family mealtimes. Journal of Health Psychology. doi: 10.1177/1359105319884600

families in sub-corpus 1 had two children. Detailed information on family constellations in subcorpus 1 are presented in Table 1:

\begin{tabular}{|c|c|}
\hline Family group & Italian (sub-corpus 1) \\
\hline Length of recordings in minutes & $20-37$ \\
\hline Mean length of recordings in minutes & 32.41 \\
\hline \multicolumn{2}{|l|}{ Participants } \\
\hline FAM_1 & FAM_4 \\
\hline Mom: Ester (38 years) & Mom: Flavia (34 years) \\
\hline Dad: Paolo (38 years) & Dad: Sergio (38 years) \\
\hline Child 1: Silverio (8 years) & Child 1: Gabriele ( 8 years and 5 months) \\
\hline Child 2: Gabriele ( 5 years and 4 months) & Child 2: Daniele (5 years and 4 months) \\
\hline FAM_2 & FAM_5 \\
\hline Mom: Marta (33 years) & Mom: Paola (40 years) \\
\hline Dad: Gianfranco (34 years) & Dad: Fabrizio (42 years) \\
\hline Child 1: Giorgia (6 years and 6 months) & Child 1: Marco ( 8 years and 6 months) \\
\hline Child 2: Clara (3 years and 10 months) & Child 2: Leonardo (5 years and 7 months) \\
\hline \multicolumn{2}{|l|}{ FAM_3 } \\
\hline \multicolumn{2}{|l|}{ Mom: Sara (37 years) } \\
\hline \multicolumn{2}{|l|}{ Dad: Matteo (37 years) } \\
\hline \multicolumn{2}{|l|}{ Child 1: Samuele ( 7 years and 11 months) } \\
\hline \multicolumn{2}{|l|}{ Child 2: Adriana (5 years and 4 months) } \\
\hline Mothers & 5 \\
\hline Fathers & 5 \\
\hline Adults, total & 10 \\
\hline Sons & 7 \\
\hline Daughters & 3 \\
\hline Children, total & 10 \\
\hline Children aged from 3 to 6 & 5 \\
\hline Older siblings & 5 \\
\hline Total participants & 20 \\
\hline
\end{tabular}

Table 1: Sub-corpus 1 - Italian families.

Sub-corpus 2 consists of 15 video-recorded meals in five Swiss families, all residents in the Lugano area. The creation of sub-corpus 2 (Swiss families) took place from December 2008 to November 2009. Families had two or three children. The criteria adopted in the selection of the Swiss families mirror the criteria adopted in the creation of sub-corpus 1. Detailed information on family constellations in sub- corpus 2 are presented in Table 2: 
Pre-print version of the article: Bova, A. (2020). Dialogical construction of parental feeding strategies during family mealtimes. Journal of Health Psychology. doi: 10.1177/1359105319884600

\begin{tabular}{|c|c|}
\hline Family group & Swiss (sub-corpus 2) \\
\hline Length of recordings in minutes & $19-42$ \\
\hline Mean length of recordings in minutes & 35.12 \\
\hline \multicolumn{2}{|l|}{ Participants } \\
\hline FAM_1 & FAM_4 \\
\hline Mom: Luisa (38 years) & Mom: Cristina ( 34 years) \\
\hline Dad: Marco (41 years) & Dad: Massimo (36 years) \\
\hline Child 1: Luca (6 years and 8 months) & Child 1: Stefano ( 8 years and 5 months) \\
\hline Child 2: Luisa (3 years and 11 months) & Child 2: Alessandro (4 years and 6 months) \\
\hline FAM_2 & FAM_5 \\
\hline Mom: Maria (36 years) & Mom: Chiara (37 years) \\
\hline Dad: Giuseppe (38 years) & Dad: Andrea (37 years) \\
\hline Child 1: Fabio (7 years and 3 months) & Child 1: Francesco (6 years and 3 months) \\
\hline Child 2: Michela (4 years and 8 months) & Child 2: Michele (4 years and 2 months) \\
\hline \multicolumn{2}{|l|}{ Child 3: Caterina (3 years and 4 months) } \\
\hline \multicolumn{2}{|l|}{ FAM_3 } \\
\hline \multicolumn{2}{|l|}{ Mom: Sara (34 years) } \\
\hline \multicolumn{2}{|l|}{ Dad: Carlo (39 years) } \\
\hline \multicolumn{2}{|l|}{ Child 1: Manuela ( 7 years and 4 months) } \\
\hline \multicolumn{2}{|l|}{ Child 2: Filippo (5 years and 1 month) } \\
\hline \multicolumn{2}{|l|}{ Child 3: Carlo (3 years and 1 month) } \\
\hline Mothers & 5 \\
\hline Fathers & 5 \\
\hline Adults, total & 10 \\
\hline Sons & 8 \\
\hline Daughters & 4 \\
\hline Children, total & 12 \\
\hline Children aged from 3 to 6 & 7 \\
\hline Older siblings & 5 \\
\hline Total participants & 22 \\
\hline
\end{tabular}

Table 2: Sub-corpus 2 - Swiss families.

All participants are Italian-speaking. Although the data corpus on which this study is based is constituted of families of two different nationalities, a cultural comparison aimed at singling out argumentative differences and commonalities between the two sub-corpora is not a goal of this study.

\section{Recruitment of the Families}

The families were selected through the snowball technique, also known as chain referral sampling (Goodman, 1961; Heckathorn, 1997, 2002) by which the families contacted helped the 
Pre-print version of the article: Bova, A. (2020). Dialogical construction of parental feeding strategies during family mealtimes. Journal of Health Psychology. doi: 10.1177/1359105319884600

researchers to find others. After initial contact by phone, the researchers visited the families in their own homes, and they described to parents the research plan. The families were informed that this study aimed to investigate the style of their mealtime conversations, but nothing was said about the specific interest in argumentative discussions about food. Participating families did not receive any financial reimbursement for their participation in the study. At the end of the transcription phase, the families were given a copy of the video as a token of gratitude for their participation.

\section{Ethical Issues}

Collecting parent-child mealtime interactions poses several challenges because respecting the privacy of the participants is one of the most critical issues in research (Berg and Lune, 2012; Salkind, 2003; Taylor and Bogdan, 1998). The ethical framework that guided this study included informed consent from the participants, anonymity, and confidentiality. All parents were approached through an information sheet outlining in clear language the general purpose of the study and providing information about how the video data would be used. Consent letters were written in accordance with Swiss Psychological Society (SPS) and the American Psychological Association (APA) guidelines, precisely the format outlined in the sixth edition of the Publication Manual of the American Psychological Association (APA, 2009). As specified in a release letter signed by the researchers and all the parents, families gave us permission to videorecord the mealtimes, provided the data would be used only for scientific purposes and privacy would be guarded. The families were assured that their anonymity would be maintained at all stages of the study, through the use of a single master sheet that contained the name of each participant and their participant number. Transcriptions, video-recorded material, and information on the families were treated in the strictest confidence and seen only by researchers. Segments of video-recorded data were used for research purposes only. The package also made clear to participants that they could choose to withdraw from the study at any time and that any concerns they had about the ethics of the research could be referred to the researchers for clarification at any time.

\section{Transcription Procedures}

All family meals were fully transcribed adopting the CHILDES standard transcription system CHAT (MacWhinney, 2000) and revised by two researchers until a high level of consent (agreement rate $=80 \%$ ) has been reached. Verbal utterances and nonverbal expressions with a clear communicative function relevant to the meal activity were identified and clearly described in the transcription. This methodology allowed a detailed analysis of verbal interactions among family members during the recording sessions. Afterward, the researchers reviewed together with the family members all the transcriptions at their home. This procedure made it possible to 
Pre-print version of the article: Bova, A. (2020). Dialogical construction of parental feeding strategies during family mealtimes. Journal of Health Psychology. doi: 10.1177/1359105319884600

ask the family members to clarify passages that were unclear in the eyes of the researchers because of the low level of recording sound and vague words and constructions. Information on the physical setting of the mealtime, that is, a description of the kitchen and the dining table, was also made for each family meal. In the transcription of the conversations, this practice has proved very useful for understanding some passages that, at first sight, appeared unclear. The direct experience of the entire process of corpus construction, including the recording of the interaction (construction of primary data) and the transcription (construction of secondary data), has allowed both the application of the availability principle, that is, "the analytical task of recording (and, in the same way, of digitising, anonymizing transcribing, annotating, etc.) is to provide for the availability of relevant details-which indeed makes the analysis possible" (Mondada, 2006, p. 55), and a fuller experiential understanding of the specific situations.

In this article, data are presented in the English translation. In all examples, all turns are numbered progressively within the discussion sequence, and family members are identified by role (for adults) and by name (for children). In order to ensure the anonymity of children, their names in this article are pseudonyms.

\section{Analytical Approach}

The theoretical tool adopted for the analysis is the pragma-dialectical ideal model of a critical discussion (van Eemeren and Grootendorst, 2004). The pragmatic conception of the argumentative moves as speech acts in discursive exchanges is connected to other approaches to studying verbal communication, such as discursive social psychology tradition (Edwards and Potter, 1992; Hepburn and Wiggins, 2007; Potter and Wetherell, 1987). The pragma-dialectical approach of argumentation considers that argumentative speech acts are not performed in a social vacuum, but between two or more parties who are having a disagreement and interact with each other in an attempt to resolve this disagreement. This approach proposes the ideal model of a critical discussion as an ideal definition of argumentation because it does not aim to describe how argumentative discourse occurs in reality, but how it would be structured were such discourse to be solely aimed at resolving differences of opinion (van Eemeren and Grootendorst, 1992).

The ideal model of a critical discussion spells out four stages that are necessary for a dialectical resolution of differences of opinion: At the confrontation stage, it is established that there is a dispute. A standpoint, that is, the analytical term used to indicate the position taken by a party in a discussion on an issue, is advanced and questioned; at the opening stage, the decision is made to attempt to resolve the dispute by means of a regulated argumentative discussion. One party takes the role of the protagonist, which means that she or he is prepared to defend her or his standpoint by means of argumentation; the other party takes the role of antagonist, which means that she or he is prepared to challenge the protagonist systematically to defend her or his standpoint; at the argumentation stage, the protagonist defends her or his standpoint, and the 
Pre-print version of the article: Bova, A. (2020). Dialogical construction of parental feeding strategies during family mealtimes. Journal of Health Psychology. doi: 10.1177/1359105319884600

antagonist elicits further argumentation from her or him if she or he has further doubts; at the concluding stage, it is established whether the dispute has been resolved on account of the standpoint or the doubt concerning the standpoint having been retracted.

In this study, the discussions between parents and children were considered as argumentative if the following criteria were satisfied:

(i) a difference of opinion among parents and children arises around a food-related issue;

(ii) one child questions the one standpoint advanced by the parent;

(iii) the parent puts forward at least one argument either in favor of or against the standpoint being questioned.

In the first phase, we selected all the argumentative discussions that occurred in the corpus of 30 family meals $(\mathrm{N}=214)$. Later, for the scope of this study, we referred to the argumentative discussions arisen around a food-related issue $(\mathrm{N}=132)$. In order to identify the arguments put forth by parents, the analysis has been focused on the third stage of the model of critical discussion, that is, the argumentation stage.

\section{Results}

In the corpus of 132 argumentative discussions arisen around a food-related issue, parents used at least one argument in support of their directives in $\mathrm{N}=125$ argumentative discussions for a total number of $\mathrm{N}=186$ arguments. In several cases, in fact, in support of their directive, parents used more than one type of argument within the same argumentative discussion to convince their children to eat. Findings show that the arguments used by parents with their children can be ascribed to three main categories: quality and quantity, appeal to consistency, and expert opinion. A synthetic overview of the results is presented below, in Table 3:

\begin{tabular}{|l|c|}
\hline $\begin{array}{l}\text { Number of discussions in which at least one argument is advanced by parents to convince their children } \\
\text { to eat }\end{array}$ & $\mathrm{N}=132$ \\
\hline Total number of arguments advanced by parents to convince their children to eat & $\mathrm{N}=186$ \\
\hline Argument: Quality & $\mathrm{N}=80(43 \%)$ \\
\hline Argument: Quantity & $\mathrm{N}=65(35 \%)$ \\
\hline Argument: Appeal to consistency & $\mathrm{N}=23(12 \%)$ \\
\hline Argument: Expert opinion & $\mathrm{N}=18(10 \%)$ \\
\hline
\end{tabular}

Table 3: Types of arguments used by parents. 
Pre-print version of the article: Bova, A. (2020). Dialogical construction of parental feeding strategies during family mealtimes. Journal of Health Psychology. doi: 10.1177/1359105319884600

Excerpts of qualitative analysis of the arguments used by parents will be presented for each type of argument in the next sections of the article. The excerpts presented in the following sections are representative of the results obtained from the broader set of analyses conducted on the whole corpus of arguments advanced by parents to convince their children to eat during mealtimes.

\section{Quality and Quantity}

Mostly, the arguments used by parents with their children in food-related argumentative discussions refer to the quality ( $\mathrm{N}=80$; about $43 \%$ ) and quantity (too much or too little) of food $(\mathrm{N}=65$; about $35 \%)$. The argument of quality was often - but not exclusively - used by parents to convince their children that the food was good and, therefore, deserved to be eaten. Typically-but not exclusively - the parents used arguments of quantity to convince their children to eat "at least a little more" food. In the following dialogue between a mother and her 7-year-old son, Fabio, we can see how the mother used an argument of quality to convince her son to eat the potatoes:

\section{Excerpt 1.}

Swiss family 2. Participants: father (DAD, 35 years), mother (MOM, 33 years), Fabio (FAB, 7 years and 3 months), Michele (MIC, 4 years and 8 months), Caterina (CAT, 3 years and 4 months). All family members are eating, seated at the meal table. DAD sits at the head of the meal table, MOM and MIC sit on the left-hand side of DAD, while FAB and CAT sit on their opposite side.

1 *MOM: everything ((the food)) good tonight, isn't it? [talking to DAD]

2 *DAD: excellent!

\%act: $\quad$ MOM looks towards FAB

3 *MOM: good grief, Fabio has hardly eaten anything tonight [talking to DAD]

\%act: lightly clucking her tongue and shaking her head in disapproval.

4 *MOM: Fabio, you must eat the potatoes.

5. *FAB: no:: I do not want them ((the potatoes))

6. *MOM: look how crisp they are! ((baked potatoes))

7. *FAB: really?::

\%act: $\quad$ FAB starts eating the potatoes

8. *MOM: bravo Fabio!

\%act: $\quad$ FAB smiles looking at MOM

Dinner is almost over. The parents are talking with each other, while their children are finishing eating. In line 1 , the mother asks the father if he also thinks that the food served during 
Pre-print version of the article: Bova, A. (2020). Dialogical construction of parental feeding strategies during family mealtimes. Journal of Health Psychology. doi: 10.1177/1359105319884600

the meal was good. The father agrees with the mother, saying that it was excellent (line 2). Immediately after, the mother expresses her concern because, she says, her 7-year-old son, Fabio, has eaten anything during the meal (line 3). This behavior is in contrast with the excellent quality of the food recognized by both parents at the beginning of the sequence. Within the excerpt, we shall specifically focus on the dialogue between the mother and his son between line 4 and line 7 because, within this phase of their dialogue, they engage in an argumentative discussion to resolve a difference of opinion between them. The mother, in line 4, makes a claim: she tells her child, Fabio, that he must eat the potatoes. The child's reaction, in line 5, fulfills this very claim in a negative sense because he disagrees with his mother ("no:: I do not want them"). The initiative and reactive moves, in lines 4 and 5, represent the beginning of the argumentative discussion, since the mother and Fabio have two diverging standpoints: on the one hand, the mother wants Fabio to eat the potatoes, while Fabio does not want to eat them. At this point, the mother's reaction is an argument advanced to convince her son to change his opinion and eat the potatoes. One could say that the mother is not trying to convince her son to eat the potatoes, but, instead, she is ordering his son to do so. In our opinion, this is not the case. As observed in previous studies devoted to argumentative interactions in families with young children, parental directives are often mitigated by persuasion (Arcidiacono and Bova, 2015; Bova and Arcidiacono, 2018). The mother's argument, in line 6, refers to the quality of the potatoes and, in particular, aims at emphasizing the good taste of the food, coherently to what has been previously attested by both parents (lines 1 and 2). The child's reaction, in line 7, fulfills his mother's argument in a positive sense, since the child appears to be persuaded by the argument of quality put forward by the mother and starts eating the potatoes. In this case, mother and child are successful in the process of negotiation between their diverging views (eating vs not eating the potatoes). The nonverbal act by the child represents the conclusion of the argumentative discussion and shows the efficacy of the mother's argumentation to convince the child to eat.

In some cases, the argument of quality and the argument of quantity were used together within the same argumentative discussion by parents, as in the following dialogue between a father and his 5-year-old son, Gabriele:

\section{Excerpt 2.}

Italian family 1. Family members: father (DAD, 38 years), mother (MOM, 38 years), Silverio (SIL, 8 years), and Gabriele (GAB, 5 years and 4 months). All family members are eating, seated at the meal table. DAD sits at the head of the meal table. MOM and GAB sit on the right-hand side of DAD, while SIL sits on their opposite side.

\%sit: $\quad$ GAB is drinking a carbonated soft drink

1. $*$ DAD: that is enough, Gabriele!

\%act: $\quad$ GAB stops drinking

$\rightarrow$ *DAD: now I will give you some rice.

2. *GAB: no, I do not want anything else: ((sitting on the chair)) 
Pre-print version of the article: Bova, A. (2020). Dialogical construction of parental feeding strategies during family mealtimes. Journal of Health Psychology. doi: 10.1177/1359105319884600

3. *DAD: the rice with tomato sauce

\%pau: $\quad 1.0 . \mathrm{sec}$

4. *GAB: please, no more. [:! shaking his head in refusal]

5. *DAD: no:: you have not eaten enough.

6. *GAB: no:::

\%act: $\quad$ GAB gets up and runs into another room

This sequence starts when the father tells his son, Gabriele, that he must stop drinking a carbonated soft drink and that he has to start eating some rice (line 1). The child's reaction, in line 2, fulfills this very claim in a negative sense because he disagrees with his father ("no, I do not want anything else:"). The initiative and reactive moves, in lines 1 and 2 , represent the confrontation stage of their argumentative discussion, since the father and Gabriele have two diverging standpoints: on the one hand, the father wants Gabriele to eat some rice, while Gabriele does not want to eat anything else. At this point, the father's reaction is an argument advanced to convince his child to change his opinion and eat the rice: in line 3 , he puts forward an argument based on the quality of food: "(it is) the rice with tomato sauce." In this case, we can suppose that, according to the father, the fact that the tomato sauce is an appetizing ingredient, and it is, therefore, a positive quality of this dish, a premise shared by him and his son. However, as we can observe from Gabriele's answer (line 4), the argument of quality put forward by the father is not sufficient to convince him to accept the father's standpoint and retract his opposite standpoint. In line 5, the father puts forward a second argument to convince Gabriele to eat the rice. The second argument put forward by the father does not refer to the quality of the food but, instead, to its quantity. The father tells his child that he has to eat a little more rice because, until that moment, he has not eaten enough. In argumentative terms, this phase of the discussion represents the argumentation stage. Despite his father's argumentative effort, Gabriele still disagrees with his father and does not accept to eat the rice (line 6). The concluding stage of this argumentative discussion involves the nonverbal act of the child getting up from the table and running into another room.

In the corpus, other examples of arguments of quality and quantity put forward by parents include the following: "no, you can't eat this ((cheese)), it's too salty," "they are not that many, and are also tasty ((chickpeas))," and "you must eat a little of meat, at least a little bit."

\section{Appeal to Consistency}

Another type of argument used by parents with their children refers to the consistency with past behaviors $(\mathrm{N}=23$; about $12 \%)$. This type of argument can be described through the following question: "If you have explicitly or implicitly affirmed it in the past, why are not you maintaining it now?" The next example illustrates this type of argument: the protagonists of the dialogue are a mother and her 4-year-old daughter, Clara: 
Pre-print version of the article: Bova, A. (2020). Dialogical construction of parental feeding strategies during family mealtimes. Journal of Health Psychology. doi: 10.1177/1359105319884600

\section{Excerpt 3.}

Italian family 2. Family members: father (DAD, 34 years), mother (MOM, 33 years), Giorgia (GIO, 6 years and 6 months), and Clara (CLA, 3 years and 10 months). All family members are seated at the meal table. DAD sits at the head of the meal table, MOM and GIO sit on the righthand side of DAD. CLA sits on the opposite side.

$1 \quad *$ MOM: Clara, do you want some rice?

$\rightarrow \quad *$ MOM: $\quad$ yellow risotto with meatballs?

2. *CLA: no:: I do not want the risotto.

3. *MOM: it is made with saffron!

4. *CLA: and what is that?

5. *DAD: it is a yellow powder

6. *MOM: but when you were a baby you used to like it

$\rightarrow \quad *$ MOM: $\quad$ you used to like it very much!

It has been 15 minutes since the dinner is started, and all family members are eating the main course. In this dialogue, Clara and her mother have a difference of opinion: the mother wants to give Clara some risotto (line 1), but Clara disagrees with her mother and does not want to eat it (line 2). We can observe that the mother in lines 1 and 3 puts forward two arguments of quality to convince her daughter to eat the risotto: "yellow risotto with meatballs?" (line 1) and "it is made with saffron!" (line 3). In this sequence, our focus is, however, on the argument put forward by the mother, in line 6: "but when you were a baby, you used to like it." This intervention permits the mother to make clear to her daughter that what she is going to eat is not something unknown, a dish to be wary of and to avoid, but rather a dish she has already eaten in the past and used to like very much. In sustaining her argumentation, the mother used the marker "but." Even if we can never be sure about what goes on in another person's mind, we can assume that this choice is because she wants to underline the contradiction between the previous behavior of her daughter, that is, you used to like it very much, and her non-consistent reaction, that is, she does not want to eat it now. The reasoning used by the mother to support her standpoint, that is, Clara must eat some risotto, is based on the logical form "as X, so Y" (given the consistency of the first element, the second element is then justified). In other words, by referring to an action which Clara did in the past and emphasizing how good that event was for her ("you used to like it very much"), the mother asks her daughter to behave in a rationale way, that is, to be consistent with the same behavior she had in the past now in the present.

In the corpus, other examples of arguments that refer to the consistency with past behaviors put forward by parents are the following: "you ate many mushrooms last night," "but how can you say that you do not like ((lemon)) if you have never tried it?," and "you usually eat many tortellini." 
Pre-print version of the article: Bova, A. (2020). Dialogical construction of parental feeding strategies during family mealtimes. Journal of Health Psychology. doi: 10.1177/1359105319884600

\section{The Argument from Expert Opinion}

The third type of argument put forward by parents in food-related argumentative discussions with their children is the argument from expert opinion $(\mathrm{N}=18$; about 10\%). This type of argument can be described through the following statement: "The person $\mathrm{X}$ is an expert. The person $\mathrm{X}$ told me $\mathrm{Y}$. Therefore, $\mathrm{Y}$ is true." The following dialogue between a mother and her 5 year-old son, Filippo, offers a clear illustration of this type of argument:

\section{Excerpt 4.}

Swiss family 3. Family members: father (DAD, 39 years), mother (MOM, 34 years), Manuela (MAN, 7 years and 4 months), Filippo (FIL, 5 years and 1 month), and Carlo (CAR, 3 years and 1 month). All family members are eating, seated at the meal table. DAD sits at the head of the meal table. MOM and MAN sit on the left-hand side of DAD, while FIL sits on their opposite side.

1. *MOM: Filippo, you must eat a little of this cheese

2. *FIL: no.

3. *MOM: $\quad$ yes, because just bread is not enough

4. $\quad$ FFIL: no, I do not want cheese

5. *MOM: this is the one Grandpa bought, though::

$6 \quad *$ MOM: $\quad$ it is delicious!

7. $*$ FIL: really?

8. *MOM: $\quad$ yes, Grandpa bought it!

9. $\quad$ FIL: $\quad$ mhm:: ((he seems thoughtful))

10. *MOM: it is delicious!

\%act: $\quad$ MOM puts a piece of cheese in FIL plate

The dinner has been in progress for about 15 minutes. This sequence starts with the mother, in line 1, making a claim: she tells her son, Filippo, that he must eat a little cheese along with his bread. The child's reaction, in line 2, fulfills this very claim in a negative sense because he does not want to eat the cheese ("no"). In argumentative terms, the mother's standpoint, that is, Filippo must eat a little cheese, has been met by the child's refusal. The initiative and reactive moves, in lines 1 and 2, represent therefore the confrontation stage of their argumentative discussion, since the mother and the child, Filippo, have divergent views on a food-related issue. In line 3, the mother reacts to her son's opposition by advancing an argument of quantity to convince Filippo to withdraw his opposite standpoint: "Because bread alone is not enough." However, the child, in line 4, reacts to his mother's argument reasserting his original position: "No, I do not want cheese." At this point, the mother puts forward two further arguments to convince the child to change his opinion. The first argument, that is, "This is the one Grandpa bought," in line 5, is an argument from expert opinion, while the second argument, that is, "it is 
Pre-print version of the article: Bova, A. (2020). Dialogical construction of parental feeding strategies during family mealtimes. Journal of Health Psychology. doi: 10.1177/1359105319884600

delicious," in line 6, is an argument of quality. These two arguments, more than the first one, succeed in catching the child's attention ("really?" line 7). In the attempt to convince her child to change his opinion, the mother repeats once again the same two arguments, in line 8 and line 10. A nonverbal act - the mother puts a piece of cheese on the child's plate-represents the end of this argumentative discussion. The child goes on to eat the cheese, showing that he accepted his mother's standpoint.

In this example, we want to stress the attention on the argument from expert opinion advanced by the mother in line 5 and line 8 ("This is the one Grandpa bought"). The mother refers to her son's grandfather as a source of expert opinion to convince the child to accept her standpoint and eat a little cheese along with his bread. In this case, the child accepts the mother's argumentation and withdraws his opposite standpoint. We cannot know if the Grandfather is indeed an expert figure, but what matters here is that in the child's eyes, his grandfather is an outstanding expert. The mother bases her argumentation on the nature of the grandfathergrandson relationship and on the feelings that are at the ground of this specific relationship, that is, the Grandfather loves his Grandson, and vice versa. Therefore, it is an argument from expert opinion based on the certainty of positive feelings, rather than on the fear of punishment (cf. Bova and Arcidiacono, 2013a). Another aspect highlighted from this study concerns the level of knowledge that the child has of the adult who represents the source of expert opinion. When parents refer to another adult as a source of expert opinion, we observed that the parents always refer to an adult who is well-known and has positive feelings toward the child such as a grandparent or a teacher. This result is in line with what has been observed by Sarangapani (2003) and Bova (2015c) who highlighted sources that according to children possess epistemic authority, including teachers, grandparents, and older peers. According to these authors, any knowledge presented by these sources is considered believable by children and rarely, if ever, questioned. Further investigation in this direction is undoubtedly necessary.

In the corpus, other examples of arguments from expert opinion put forward by parents include the following: "no sweetheart, trust me because I know what I am talking about... sometimes you can try, other times you cannot try, and you must trust what parents tell you" and "you cannot have the lemons because I ((mom)) need the lemons."

\section{Discussion}

The parent-child argumentative discussions during mealtimes are an object of research which can provide us with much information on how food is routinely negotiated by and between parents and children. In particular, the focus on the argumentative discussions permits us to understand how family members manage their differences of opinions. This study has shown how the resolution of the difference of opinion on food-related issues between parents and children during mealtimes emerges as a process of negotiation between diverging views on the 
Pre-print version of the article: Bova, A. (2020). Dialogical construction of parental feeding strategies during family mealtimes. Journal of Health Psychology. doi: 10.1177/1359105319884600

subject matter. Argumentation between parents and children during mealtimes does not start from an affirmative reply. Instead, parents advance arguments only in reaction to a rejection of their standpoint or at least from doubts about it by their children. By engaging in argumentative discussions, parents accept the commitment to clarifying to their children the reasons on which rules and prescriptions about food are based, while children can become more aware of being full-fledged active participants of their family (Bova, 2019; Bova and Arcidiacono, 2018). Family argumentative interactions should, therefore, be viewed as a bidirectional process of mutual apprenticeship in which parents affect children and are simultaneously affected by them (cf. Pontecorvo et al., 2001).

Argumentation in the family context, as in all the different types of interpersonal interactions (Bova and Arcidiacono, 2017), cannot but be dialogical. The structure of parentchild argumentative discussions, in fact, is constituted by the interaction between initiative and reactive moves which are aimed at resolving their differences of opinion. Despite the differences in age, roles, and competencies between parents and children, in this study, we have seen that parents and children together dialogically constructed the process of negotiating their divergent opinions on food-related issues. On the one hand, the parents advance arguments to convince their children to eat (or not to eat more) a particular food served during the meal; on the other hand, the children try to convince their parents that the quality of the food is not good or that the amount is too much (or not enough). Accordingly, parents and children aim to convince the other party to change or retract her or his initial standpoint.

At this juncture, it seems appropriate to take stock of the findings of our study. What are the arguments most used by parents to convince their children to eat during mealtime conversations? In line with previous studies (Wiggins, 2013), the findings of this study show that parents during food-related discussions with their children mostly put forward arguments that refer to the concepts of quality and quantity of food. The argument of quality is frequently - but not exclusively - put forward by parents to convince their children that the food is good and therefore deserves to be eaten. On the contrary, children typically - but, also in this case, not exclusively_ put forward arguments of quality to refute eating the food prepared by their parents, by highlighting the bad quality of that food. The argument of quantity is put forward by parents and children with the same scope of when they put forward arguments of quality. As we have seen in excerpt 2, the argument of quality and the argument of quantity can also be used together by parents within an argumentative discussion with their children. Because through the arguments of quality and quantity parents highlight specific propriety (positive or negative) of food during mealtime discussions with their children, these types of arguments can be defined as "activity-bound arguments." Moreover, the parents' choice of using a language level that can be easily understood by children is a typical trait of the argumentative interactions between parents and children during mealtimes. For example, if the parents' purpose is to feed their child, the food is described as "very good" or "nutritious," and its quantity is "too little." On the contrary, 
Pre-print version of the article: Bova, A. (2020). Dialogical construction of parental feeding strategies during family mealtimes. Journal of Health Psychology. doi: 10.1177/1359105319884600

if the parents' purpose is not to feed the child further, in terms of quality the food is described as "salty" or "not good," and in quantitative terms as "it is quite enough" or "it is too much."

Compared to the arguments of quality and quantity, the other types of arguments put forward by parents, that is, appeal to consistency and argument from expert opinion, are used less frequently during food-related discussions with their children. The arguments that make an appeal to consistency, for example, in the past you used to like it, aim at showing children how our past actions are essential to justify our present actions. In line with what has been already observed by Wiggins (2014b), family members during mealtime conversations do not just make claims about food and activity-related objects, but they are also bound up with social actions and relationships in the immediate context. By advancing these arguments, parents discuss with their children the importance of behaving rationally. The type of argumentative strategy that we called appeal to consistency could, therefore, also be called "appeal to rationality." However, we opted for the first definition because it appears the most appropriate to describe all the examples we found in our corpus. Instead, by using the argument from expert opinion, for example, "this is the one Grandpa bought," parents aim to teach their children the importance of following the behaviors suggested by those people more expert than them.

Overall, the results of this study contribute to highlight how the feeding practices in families with young children during mealtimes represent a crucial educational activity in which parents and children have intensive and complex interactions. The topic of the food is, in fact, a matter of confrontation at different levels and in various contexts of the everyday lives of people: the discussion about quality and quantity of food, the related arguments about the health implications of a proper diet, and the socialization to the rules to be respected at mealtimes are socially crucial for children. The results of the observations and the subtle analyses of conversational exchanges among family members are examples of possible ways to recognize the educational value of parent-child food negotiation. This topic has to be assumed as a relevant one also by parents and other caretakers, in order to play a fundamental role in the social endeavor of feeding practices.

The consideration regarding the educational value of parent-child food negotiation during mealtimes opens the way for new research paths, not addressed in this article. The analysis of parent-child discussions should consider how what is typical or not within a specific community can affect the interlocutors' dialogical choices. Addressing and negotiating topics related to food issues is typical parental behavior at mealtimes adopted by western families (Blum-Kulka, 1997; Bova, 2019; Ochs, 2006; Pontecorvo and Fasulo, 1999). This behavior has been typical of western families for 20 or 30 years now but has not always been so. Further research in this direction is needed to understand better how features and constraints of the activity of family mealtime affect how food is routinely negotiated by and between parents and children.

We want to conclude our work with some methodological remarks. We are conscious that many challenges derive from the advantages and disadvantages of the research design adopted for this study of mealtime conversations. On the one hand, the limited number of recordings 
Pre-print version of the article: Bova, A. (2020). Dialogical construction of parental feeding strategies during family mealtimes. Journal of Health Psychology. doi: 10.1177/1359105319884600

favored a more careful analysis but did not allow certain quantifications, such as the correlation between categories. A more extensive database would probably permit more quantitatively reliable data for statistical relationships. On the other hand, careful studies of a small number of conversations in a natural setting may give rise to a more penetrating and "data-close" analysis of the argumentative discussions between parents and children. Using mealtime conversations does not automatically solve the problem of obtaining optimal family interaction data. No data are perfect. Nevertheless, we believe that mealtime conversations are a highly informative source for the study of eating practices within the family context, and generally, they are an invaluable source for studying the dynamics of family interactions within an emic perspective.

\section{Declaration of Conflicting Interests}

The author(s) declared no potential conflicts of interest with respect to the research, authorship and/or publication of this article.

\section{Funding}

The author(s) disclosed receipt of the following financial support for the research, authorship, and/or publication of this article: This work was supported by the Swiss National Science Foundation (SNSF; grant number PDFMP1-123093/1).

\section{ORCID ID}

Antonio Bova https://orcid.org/0000-0002-6371-0371

\section{References}

Alm S, Olsen SO and Honkanen P (2015) The role of family communication and parents' feeding practices in children's food preferences. Appetite 89: 112-21.

American Psychological Association (APA) (2009) Publication Manual of the American Psychological Association (6th ed.). Washington, DC: American Psychological Association.

Arcidiacono F and Bova A. (2015) Activity-bound and activity-unbound arguments in response to parental eat-directives at mealtimes: Differences and similarities in children of 3-5 and 6-9 years old. Learning, Culture and Social Interaction 6: 40-55.

Berg BL and Lune H (2012) Qualitative Research Methods for the Social Sciences (8th ed.). Boston, MA: Pearson.

Billig M (1987) Arguing and Thinking. Cambridge: Cambridge University Press. 
Pre-print version of the article: Bova, A. (2020). Dialogical construction of parental feeding strategies during family mealtimes. Journal of Health Psychology. doi: 10.1177/1359105319884600

Birch LL and Davison KK (2001) Family environmental factors influencing the developing behavioral controls of food intake and child overweight. Pediatric Clinics of North America 48(4): 893-907.

Birch LL and Fisher JO (2000) Mothers' child-feeding practices influence daughters' eating and weight. Am J Clin Nutr 71(5): 1054-61.

Black MM and Hurley KM (2017) Responsive Feeding: Strategies to Promote Healthy Mealtime Interactions. Nestle Nutr Inst Workshop Ser 87: 153-165.

Blum-Kulka S (1997) Dinner Talk: Cultural Patterns of Sociability and Socialization in Family Discourse. Mahwah, NJ: Erlbaum.

Boutelle KN, Lytle LA, Murray DM, Birnbaum AS and Story M (2001) Perceptions of the family mealtime environment and adolescent mealtime behavior: do adults and adolescents agree? J Nutr Educ 33(3): 128-33.

Bova A (2015a) Adult as a source of expert opinion in child's argumentation during family mealtime conversations. Journal of Argumentation in Context 4(1): 4-20.

Bova A (2015b) Favoring argumentative disciplinary discussions in the classroom. A study of teacher's questions at undergraduate and graduate level. Learning, Culture and Social Interaction 7: 97-108.

Bova A (2015c) "This is the cheese bought by Grandpa". A study of the arguments from authority used by parents with their children during mealtimes. Journal of Argumentation in Context 4(2): 133-157.

Bova A (2019) The Functions of Parent-Child Argumentation. Cham: Palgrave Macmillan.

Bova A and Arcidiacono F (2013a) Invoking the authority of feelings as a strategic maneuver in family mealtime conversations. Journal of Community and Applied Social Psychology 23(3): 206-224.

Bova A and Arcidiacono F (2013b) Investigating children's Why-questions. A study comparing argumentative and explanatory function. Discourse Studies 15(6): 713-734.

Bova A and Arcidiacono F (2014) "You must eat the salad because it is nutritious". Argumentative strategies adopted by parents and children in food-related discussions at mealtimes. Appetite 73: 81-94.

Bova A and Arcidiacono F (2015) Beyond conflicts. Origin and types of issues leading to argumentative discussions during family mealtimes. Journal of Language Aggression and Conflict 3(2): 263-288.

Bova A and Arcidiacono F (2017) Interpersonal dynamics within argumentative interactions: An introduction. In: Arcidiacono F and Bova A (eds) Interpersonal Argumentation in Educational and Professional Contexts. New York: Springer, pp. xvii-xxii.

Bova A and Arcidiacono F (2018) Interplay between parental argumentative strategies, children's reactions, and topics of disagreement during mealtime conversations. Learning, Culture and Social Interaction 19: 124-133. 
Pre-print version of the article: Bova, A. (2020). Dialogical construction of parental feeding strategies during family mealtimes. Journal of Health Psychology. doi: 10.1177/1359105319884600

Brumark ^ (2008) "Eat your hamburger!” - "No, I don’t want to!” Argumentation and argumentative development in the context of dinner conversation in twenty Swedish families. Argumentation 22(2): 251-271.

Burnier D, Dubois L and Girard M (2011) Arguments at mealtime and child energy intake. $J$ Nutr Educ Behav 43(6): 473-81.

Draxten M, Fulkerson JA, Friend S, Flattum CF and Schow R (2014) Parental role modeling of fruits and vegetables at meals and snacks is associated with children's adequate consumption. Appetite 78: 1-7.

Drucker RR, Hammer LD, Agras WS and Bryson S (1999) Can mothers influence their child's eating behaviour? Journal of Developmental Behavioural Paediatrics 20: 88-92.

Edwards D and Potter J (1992) Discursive Psychology. London: Sage.

Egbert MM (1997) Schisming: The collaborative transformation from a single conversation to multiple conversations. Research on Language Social Interaction 30(1): 1-51.

Fiese BH, Foley KP and Spagnola M (2006) Routine and ritual elements in family mealtimes: Contexts for child well-being and family identity. New Directions for Child and Adolescent Development 111: 67-89.

Finnane JM, Jansen E, Mallan KM and Daniels LA (2017) Mealtime structure and responsive feeding practices are associated with less food fussiness and more food enjoyment in children. J Nutr Educ Behav 49(1): 11-18.

Foster JS, Grenier RS and Mobley AR (2017) Discourse Analysis-A Potential Analytical Technique for Nutrition Research. J Nutr Educ Behav 49(7): S17.

Foster JS, Grenier RS, Taylor EA and Mobley AR (2019) Discourse Analysis: A Novel Analytical Technique for Qualitative Nutrition Research. J Nutr Educ Behav in press.

Fulkerson JA, Neumark-Sztainer D and Story M (2006) Adolescent and parent views of family meals. J Am Diet Assoc 106(4): 526-532.

Fulkerson JA, Story M, Neumark-Sztainer D and Rydell S (2008) Family meals: perceptions of benefits and challenges among parents of 8- to 10-year-old children. J Am Diet Assoc 108(4): 706-709.

Goodell LS, Johnson SL, Antono AC, Power TG and Hughes SO (2017) Strategies Low-Income Parents Use to Overcome Their Children's Food Refusal. Matern Child Health J 21(1): 6876.

Goodman LA (1961) Snowball sampling. Annals of Mathematical Statistics 32(1): 148-170.

Goodwin MH (1997) Byplay: Negotiating evaluation in storytelling. In: Guy GR, Feagin C, Schiffrin D and Baugh J (eds) Towards a social science of language papers in honour of William Labov. Amsterdam/Philadelphia: John Benjamins, pp. 77-102.

Grace GW (1987) The Linguistic Construction of Reality. London: Croom Helm.

Greco S, Perret-Clermont AN, Iannaccone A, Rocci A, Convertini J and Schaer R (2018) The analysis of implicit premises within children's argumentative inferences. Informal Logic 38(1): 438-470. 
Pre-print version of the article: Bova, A. (2020). Dialogical construction of parental feeding strategies during family mealtimes. Journal of Health Psychology. doi: 10.1177/1359105319884600

Heckathorn DD (1997) Respondent-driven sampling: A new approach to the study of hidden populations. Social Problems 44(2): 174-199.

Heckathorn DD (2002) Respondent-driven sampling II: Deriving valid estimates from chainreferral samples of hidden populations. Social Problems 49(1): 11-34.

Heller V (2014) Discursive practices in family dinner talk and classroom discourse: A contextual comparison. Learning, Culture and Social Interaction 3(2): 134-145.

Hepburn A and Wiggins S (2007) Discursive Research in Practice: New Approaches to Psychology and Everyday interaction. Cambridge: Cambridge University Press.

Hubbs-Tait L, Kennedy TS, Page MC, Topham GL and Harrist AW (2008) Parental feeding practices predict authoritative, authoritarian, and permissive parenting styles. Journal of the American Dietetic Association 108: 1154-1161.

Hughes SO, Power TG, Papaioannou MA, Cross MB, Nicklas TA, Hall SK and Shewchuk RM (2011) Emotional climate, feeding practices, and feeding styles: An observational analysis of the dinner meal in Head Start families. International Journal of Behavioral Nutrition and Physical Activity 8(60): 1-11.

Kuhn D (1991) The skills of argument. New York, NY: Cambridge University Press.

Laurier E and Wiggins S (2011) Finishing the family meal. The interactional organisation of satiety. Appetite 56(1): 53-64.

Lerner GH (2002) Turn-sharing: The choral co-production of talk-in-interaction. In: Ford C, Fox $\mathrm{B}$ and Thompson S (eds) The language of turn and sequence. Oxford: Oxford University Press, pp. 225-256.

Loth KA, Nogueira de Brito J, Neumark-Sztainer D, Fisher JO and Berge JM (2018) A qualitative exploration into the parent-child feeding relationship: How parents of preschoolers divide the responsibilities of feeding with their children. $J$ Nutr Educ Behav 50(7): 655-667.

MacWhinney B (2000) The CHILDES Project: Tools for Analyzing Talk (3rd ed.). Mahwah, NJ: Erlbaum.

Mondada L (2006) Video recording as the preservation of fundamental features for analysis. In: Knoblauch H, Raab H, Soeffner HG and Schnettler B (eds) Video Analysis. Bern: Lang, pp. 51-68.

Mondada L (2009) The methodical organization of talking and eating: Assessments in dinner conversations. Food Quality and Preference 20(8): 558-571.

Morton H, Campbell K, Santich B and Worsley A (1999) Parental strategies and young children's snacking behaviour: A pilot study. Australian Journal of Nutrition and Dietetics 56(4): 215-220.

Ochs E (2006) The cultural structuring of mealtime socialization. New Directions for Child and Adolescent Development 111: 35-49. 
Pre-print version of the article: Bova, A. (2020). Dialogical construction of parental feeding strategies during family mealtimes. Journal of Health Psychology. doi: 10.1177/1359105319884600

Pan BA, Perlmann RY and Snow CE (2000) Food for thought: Dinner table as a context for observing parent-child discourse. In: Menn L and Ratner NB (eds) Methods for studying language production. Mahwah, NJ: Erlbaum, pp. 205-224.

Patrick H, Nicklas TA, Hughes SO and Morales M (2005) The benefits of authoritative feeding style: Caregiver feeding styles and children's food consumption patterns. Appetite 44: 243249.

Patton SR, Dolan LM and Powers SW (2006) Mealtime interactions relate to dietary adherence and glycemic control in young children with type 1 diabetes. Diabetes Care 29(5): 10021006.

Pesch MH, Miller AL, Appugliese DP, Rosenblum KL and Lumeng JC (2018) Mothers of obese children use more direct imperatives to restrict eating. J Nutr Educ Behav 50(4): 403-407.

Pontecorvo C and Fasulo A (1999) Planning a typical Italian meal: A family reflection on culture. Culture Psychology 5(3): 313-335.

Pontecorvo C, Fasulo A and Sterponi L (2001) Mutual apprentices: The making of parenthood and childhood in family dinner conversations. Human Development 44(6): 340-361.

Potter J and Wetherell M (1987) Discourse and Social Psychology: Beyond Attitudes and Behaviour. London: Sage Publications

Roach E, Viechnicki GB, Retzloff LB, Davis-Kean P, Lumeng JC and Miller AL (2017) Family food talk, child eating behavior, and maternal feeding practices. Appetite 117: 40-50.

Russell CG, Worsley A and Campbell KJ (2015) Strategies used by parents to influence their children's food preferences. Appetite 90: 123-30.

Salkind NJ (2003) Exploring Research (5th ed.). Upper Saddle River, NJ: Prentice Hall.

Sarangapani PM (2003) Constructing School Knowledge: An Ethnography of Learning in an Indian Village. New Delhi: SAGE.

Scaglioni S, Salvioni M and Galimberti C (2008) Influence of parental attitudes in the development of children eating behaviour. British Journal of Nutrition 99 (1):22-25.

Tannen D (1990) You Just Don't Understand: Women and Men in Conversation. New York, NY: Morrow.

Taylor SJ and Bogdan R (1998) Introduction to Qualitative Research Methods (3rd ed.). New York, NY: Wiley.

van Eemeren FH and Grootendorst R (1992) Argumentation, Communication, and Fallacies. A Pragma-Dialectical Perspective. Hillsdale, NJ: Erlbaum.

van Eemeren FH and Grootendorst R (2004) A Systematic Theory of Argumentation: The Pragma-Dialectical Approach. Cambridge: Cambridge University Press.

Voss JF and Van Dyke JA (2001) Argumentation in psychology: Background comments. Discourse Processes 32(2-3): 89-111.

Weigand E (2006) Argumentation: The Mixed Game. Argumentation 20(1): 59-87.

Wiggins S (2004a) Good for "you": Generic and individual healthy eating advice in family mealtimes. Journal of Health Psychology 9(4): 535-548. 
Pre-print version of the article: Bova, A. (2020). Dialogical construction of parental feeding strategies during family mealtimes. Journal of Health Psychology. doi: 10.1177/1359105319884600

Wiggins S (2004b) Talking about taste: Using a discursive psychological approach to examine challenges to food evaluations. Appetite 43(1): 29-38.

Wiggins S (2013) The social life of 'eugh': Disgust as assessment in family mealtimes. British Journal of Social Psychology 52(3): 489-509.

Wiggins S (2014a) Adult and child use of love, like, don't like and hate during family mealtimes: Subjective category assessments as food preference talk. Appetite 80: 7-15.

Wiggins S (2014b). On the accountability of changing bodies: Using discursive psychology to examine embodied identities in different research settings. Qualitative Psychology 1(2): 144-162. 